\title{
EL CONCEPTO DE REPARACIÓN COLECTIVA EN EL MARCO DE LA JUSTICIA TRANSICIONAL ${ }^{1}$
}

The Concept of Collective Redress in the Context of Transitional Justice ${ }^{1}$

\section{Mary Cruz Ortega Hernández ${ }^{2}$ Rafaela Sayas Contreras ${ }^{3}$}

Fecha de Recepción: Mayo 5 de 2014

Fecha de Aceptación: Mayo 12 de 2014

SUMARIO: 1. Introducción, Metodología; 2. Justicia transicional: concepto y elementos; 3. Elementos teóricos de la reparación colectiva, a. Los sujetos de reparación, $b$. Los derechos vulnerados y el daño colectivo, c. Las medias de reparación colectiva; 4. Características de los procesos de reparación colectiva,

a. Procesos participativos, b. La Integralidad del proceso de reparación colectiva, $c$. La perspectiva transformadora; 5. Conclusiones; 6. Referencias bibliográficas.

\footnotetext{
${ }^{1}$ Investigación concluida desarrollada en el Marco de la Línea de justicia transicional y Derechos Humanos del grupo Conflicto y Sociedad de la Universidad de Cartagena, en el marco de la Convocatoria de Financiación interna para el Fortalecimiento de Grupos Reconocidos por Colciencias 2013.

${ }^{2}$ Abogada de la Universidad de Cartagena, Magíster en Derechos Humanos Interculturalidad y Desarrollo, consultora en Derechos Humanos, miembro del Grupo de Investigación Conflicto y Sociedad de la Universidad de Cartagena, Categoría A Colciencias temenanqui@hotmail.com

${ }^{3}$ Abogada, docente investigadora de la Universidad de Cartagena y consultora en Derechos Humanos, Magíster en Derecho por la Universidad Nacional de Colombia y PhD. En Sociología por la Universidad de Belgrano en Buenos Aires (Argentina). Directora del Grupo Conflicto y Sociedad de la Universidad de Cartagena. Categoría A Colciencias. rafaelaester@gmail.com
} 


\section{COMO SE CITA ESTE ARTÍCULO (APA 6)}

Ortega Hernández, M. C., Sayas Contreras R. (2014) El concepto de reparación colectiva en el marco de la justicia transicional. (Y. Carrillo De la rosa, Ed.) Revista Jurídica Mario Alario D'Filippo, VI (12), pág. 38-55

\section{RESUMEN}

El concepto de reparaciones colectivas, como categoría jurídica independiente de las reparaciones individuales, nace de la mano del Derecho Internacional de los Derechos Humanos, con el fin de favorecer a las víctimas de violaciones de Derechos Humanos en el marco de las políticas públicas de los Estados nacionales. Esta nueva categoría en construcción interpela los elementos tradicionales de la teoría jurídica, en la medida en que desborda los límites de la reparación individual, en el marco de procesos que atienden violaciones contra pueblos y comunidades. En ese sentido, este trabajo da cuenta del desarrollo del concepto y sus alcances, visibilizándose sus complejidades y limitaciones para ofrecer una propuesta conceptual que integre todos sus elementos.

\section{ABSTRACT}

The concept of collective reparations, as a separate legal category of individual reparations, comes from the hand of the International Law of Human Rights, in order to encourage the victims of human rights violations in the context of public policies of States nationals. This new category under construction challenges the traditional elements of legal theory, to the extent that goes beyond the limits of individual reparation, in the framework of processes dealing violations against peoples and communities. In that sense, this paper is about the development of the concept and its scope, its complexities and limitations to provide a conceptual proposal that integrates all its elements.

\section{PALABRAS CLAVE}

Víctimas, Reparación colectiva, justicia transicional, derechos colectivos, daños colectivos.

\section{KEYWORDS}

Victims, Collective redress, transitional justice, collective rights, collective damages. 


\section{INTRODUCCIÓN}

La teoría jurídica tradicional ha establecido reglas para las reparaciones por daños ocasionados a causa de injustos sufridos, históricamente estas reglas han tenido mayor impacto en lo relacionado con el derecho penal y el derecho administrativo, dentro de la división clásica de las ramas del derecho, atinente al concepto tradicional de perjuicios en el marco del derecho de daños y desde una perspectiva individual.

Con el desarrollo de Derechos Humanos y sus mecanismos de protección, se extiende el concepto de reparación propuesto por la teoría jurídica tradicional al campo de las violaciones al Derecho Internacional de los Derechos humanos y del derecho Internacional Humanitario, es así como se van decantando instrumentos de carácter internacional que establecen reglas y principios de reparación. Los primeros avances se orientaron hacia el concepto de reparaciones individuales, con lo cual, pensar en reparaciones de daños colectivas exigían otro tipo de desarrollos conceptuales.

Así las cosas, las realidades de países que se encuentran o se han encontrado en situación de masiva y sistemática violación de derechos humanos, cualquiera sea la causa que la produce, ha demostrado que existen daños concretos, no a individuos por separado, sino a los grupos y comunidades a los que estos pertenecen, siendo estos grupos y comunidades un ente diferente a la suma de sus individuos.

Frente a estas realidades la teoría tradicional en materia de reparaciones se queda corta, luego entonces las reparaciones no alcanzarían la restitutio in integrum, por lo que se han venido redefiniendo nuevos esquemas y rutas de reparación colectivas (de la mano de estudios territoriales/locales), de la mano de planes nacionales de reparaciones de países que han salido de conflictos armados y se encuentran en el marco de lo que se ha venido denominando como justicia transicional.

En este trabajo de investigación se revisarán los esquemas que a nivel internacional se han desarrollo en cuanto al concepto de reparación colectiva, sus alcances y limitaciones

\section{METODOLOGÍA}

La presente es una investigación Jurídica de carácter cualitativo que ha sido abordada desde el análisis documental, la misma se divide en tres partes, inicia con la identificación del concepto de justicia transicional para visibilizar que el mismo es la base sobre la cual se asienta el derecho a la reparación colectiva, continua con los principales elementos teóricos con los que ha sido abordada la reparación colectiva, para finalizar con una propuesta de conceptualización de la misma que pretende integrar todos los elementos en una definición compleja

\section{JUSTICIA TRANSICIONAL: CONCEPTO YELEMENTOS}

El concepto de justicia transicional surge a finales de la década de los ochentas, como respuesta a los cambios políticos experimentados en América Latina y Europa Oriental, con la finalidad de hacer 
frente a los abusos cometidos por regímenes autoritarios que se impusieron en estas latitudes, por ejemplo en Argentina y Chile en el momento de transición hacia las democracias. Los nuevos gobiernos empiezan a implementar medidas tales como: comisiones de la verdad, leyes de punto final, normativas de alternatividad penal, diferentes reformas institucionales y mecanismos de dignificación de las víctimas.

De hecho, ha sido definida como

[E]I conjunto de decisiones y mecanismos destinados a impartir justicia en asociación con un proceso de cambio político, se ha de advertir que su desarrollo tiene como objetivo prioritario ofrecer soluciones adecuadas a la realidad social en tránsito para exigir responsabilidades y ofrecer una reparación justa a las víctimas, respecto a los abusos a gran escala perpetrados durante un previo conflicto armado -incluyendo el contexto socio-político en el que el mismo se produjo-, como consecuencia de la represión ejercida por el régimen cuya extinción y substitución se pretende o ya se ha efectuado, o bien, fruto de la dinámica de acción/represión presente en un Estado democrático en el cual las tensiones internas o la presencia de grupos terroristas comportaron en el pasado la presencia de un nivel intenso de violencia y de inestabilidad política e institucional." [...]. En segundo lugar, la justicia transicional es, en sí misma, un proceso que se desarrolla a lo largo de un período de tiempo más o menos prolongado: es, pues, un proceso dentro de otro proceso -el de transición política-; de este modo, las exigencias políticas condicionan tanto las decisiones y mecanismos de justica transicional que se adoptan como su funcionamiento real y efectivo, pero, lógicamente, la política de justicia transicional seguida es un factor que influye también en el propio desarrollo del proceso de cambio político". (Bonet, 2009, p. 12)

Encontramos entonces que la justicia transicional presenta dos dimensiones una de carácter judicial que privilegia la investigación de los hechos ocurridos para la imputación de responsabilidades a los perpetradores, y una dimensión política que integra una serie de procesos que conducen a la trasformación social e institucional de los Estados para posicionar los valores democráticos. De acuerdo con el Centro Internacional para la Justicia Transicional (ICTJ) se configura como:

“Una respuesta a las violaciones sistemáticas o generalizadas a los derechos humanos. Su objetivo es reconocer a las víctimas y promover iniciativas de paz, reconciliación y democracia. La justicia transicional no es una forma especial de justicia, sino una justicia adaptada a sociedades que se trasforman así mismas después de un período de violación generalizada de los derechos humanos." (Centro Internacional para la Justicia Transicional, 2009)

La justicia transaccional, se presenta como un momento político de sociedades que pretenden salir de períodos dictatoriales o de conflictos y tensiones, lo que implica una salida negociada de esas situaciones entre los distintos actores involucrados,

“De este modo el conflicto se resuelve por medio de la transacción, en un doble sentido, pues no solo se busca materializar un pacto para poner fin a las diferencias entre las partes implicadas, sino 
que, además, para llegar a dicho acuerdo las partes deben transigir, es decir, consentir en parte con aspectos que no se consideran justos o razonables." (Bonet, 2009)

Por lo tanto, los mecanismos y procesos de justicia transicional implican decisiones políticas y jurídicas que se salen del patrón normal de las dinámicas de los Estados pacificados, de hecho, estos son implementados para lograr una transición basada en un diálogo ampliado en el que participen los actores en conflicto, las víctimas y la sociedad, con miras al restablecimiento de la democracia. En este sentido se adoptan en el marco de estos consensos normativas que pueden llevar diversos nombres como leyes de punto final, acuerdos de paz, marcos jurídicos para la paz y otros que en el fondo no hacen más que reconocer y dignificar los derechos humanos conculcados de las víctimas y de la sociedad por los desafueros de los actores insurgentes y las fallas de Estado.

En un marco de justicia transicional se debe asegurar el cumplimiento de los derechos a la verdad, la justicia, la reparación y las garantías de no repetición. En este sentido se expresa Brito Ruiz (2010), al tratar de presentar un modelo de justicia transicional con enfoque restaurativo:

"Un proceso de justicia transicional que pretenda ser restaurativo deberá tener cuatro niveles: un primer nivel, que tiene que ver con el derecho a la verdad de las víctimas y esta materializado en las comisiones de verdad y sus informes de memoria histórica. Un segundo nivel, que tiene que ver con el derecho a la justicia y que debe comprender desarrollos jurídicos que garanticen que no exista impunidad y que la forma como se lleven los casos sea transparente y ejemplarizantes para la sociedad. Un tercer nivel, relacionado con el derecho a la reparación. Que se expresa en programas de reparación material y simbólica. Y un cuanto nivel, enfocado en la garantía de no repetición, que implica cambios en las bases culturales y estructurales de la sociedad y el estado (políticas públicas). (p.71)

Por lo tanto la justicia transicional expresa un proceso jurídico y político para la trasformación de las estructuras socio-políticas que fueron causa de conflictos y tensiones, pero al tiempo como respuesta a las graves, masivas y sistemáticas violaciones de derechos humanos no al amparo del derecho ordinario sino del Derecho Internacional de los derechos Humanos y del Derecho Internacional Humanitario. En ese marco se establecen los mecanismos que tiendan a satisfacer los derechos a la indemnización, restitución, rehabilitación, satisfacción, y garantías de no repetición para los grupos, comunidades y la sociedad misma que se han visto afectados como consecuencia de la magnitud y masificación de las violaciones; esto es desarrollar herramientas para las reparaciones individuales y colectivas, ocupémonos de la reflexión de estas últimas.

\section{ELEMENTOS TEÓRICOS DE LA REPARACIÓN COLECTIVA}

Clarificar el concepto de reparación colectiva implica determinar la existencia de titulares de derechos de naturaleza colectiva en contraposición de las víctimas individuales. En ese sentido, no resulta fácil una definición que recoja los elementos definitorios de sujetos colectivos, descripción normativa que reviste importancia en la medida que al encuadrarse un colectivo en el supuesto de hecho de la norma, calificaría -el colectivo- como titular de beneficios administrativos a cargo de una obligación estatal en el marco de un programa de reparación. En ese sentido, la reparación 
colectiva es una forma de reparación que tiene como fundamento el daño que se concreta por hechos masivos y sistemáticos violatorios de Derechos Humanos, cuyos titulares no son individuos per se, sino la agrupación de los mismos, unidos por una suerte de circunstancias históricas que los sitúan como blanco de vulneraciones, menoscabos y desintegración del tejido social en el marco de un conflicto armado o de regímenes autoritarios. Se produce con independencia de las reparaciones individuales que se establezcan, puesto que no son conceptos excluyentes.

En la actualidad conceptualmente se debaten los elementos constitutivos de este tipo de reparación, basándose en gran medida en la experiencia de países que han intentado su aplicación. La reparación colectiva es por tanto un concepto en construcción. A continuación se tocarán los elementos que integran el concepto a saber: los sujetos de reparación colectiva, los derechos vulnerados y el daño colectivo y las medidas de reparación colectiva.

\section{a. LOS SUJETOS DE REPARACIÓN COLECTIVA}

Teóricamente las reparaciones se asocian al pago de daños materiales y morales como consecuencia del inicio de acciones judiciales contra el Estado, bien sea con ocasión de fallos de reparación directa o condenas contra el Estado Colombiano por incumplimiento de obligaciones internacionales en el Marco del Sistema Interamericano de Derechos; o en el marco de programas gubernamentales de reparaciones.

En ese sentido hacer un ejercicio de lo que implica un sujeto colectivo y lo que no, y como este pueden experimentar y afectarse por perpetraciones concretas en el marco de conflictos armados o regímenes antidemocráticos, no es cuestión menor, mucho menos lo es decantar tensiones conceptuales relacionadas con el concepto "colectivo", por ejemplo, sujetos colectivos, derechos colectivos e impactos colectivos aunque las vulneraciones sean individuales, pasamos a explicarnos.

Al margen del concepto de reparación colectiva, preexiste en el derecho la idea de derechos colectivos como derechos de grupo o derechos difusos, aspecto que problematiza un poco la idea de víctimas colectivas, en ese sentido vemos como el derecho clásico da respuestas procesales para el resarcimiento de perjuicios para esos grupos vulnerados en tratándose de derechos de variada naturaleza que no se inscriben en el campo de violaciones sistemáticas de Derechos Humanos,

Y como no basta la mera consagración sustancial en el ordenamiento jurídico de esos derechos supra-individuales, los países de la familia del civil law han establecido, asimismo, diversos mecanismos procesales para (...), lograr que por vía jurisdiccional se adopten las medidas de prevención, cesación y restablecimiento de los derechos supraindividuales, se ha acudido a las acciones populares, (...). Mientras tanto, para reparar los daños causados a los intereses de la comunidad o la colectividad previamente conformadas, según se trate de derechos difusos o colectivos stricto sensu, algunas legislaciones han implementado mecanismos como la fijación de indemnizaciones globales a favor del grupo afectado. (Corte Suprema de Justicia, sentencia del 22 de abril de 2009, M.P. Edgardo Villamil Portilla Exp. No. 11001-31-03-026-2000-00624-01)

Así las cosas, en el tema específico que nos ocupa, el parámetro base de las reparaciones lo 
constituyen la reparación integral a saber: verdad, justicia, reparación y garantías de no repetición, ahora, ¿cómo vaciar estos elementos en el molde de lo colectivo? En efecto, como se puede determinar a partir de las especificidades, cuales daños afectan solo al individuo, o, que si bien afectaron a un individuo, tienen la potencialidad de afectar al colectivo o grupo, más allá de que las medidas que se otorguen sean materiales o simbólicas.

Las reparaciones colectivas no son solo simbólicas; algunas son materiales, como cuando se construye una escuela o un hospital en calidad de reparación, o se destinan a un grupo determinado. (Oficina del Alto Comisionado de las Naciones Unidas para los Derechos Humanos, 2006)

Según Naciones Unidas (2006), podemos observar tres elementos de la reparación colectiva: los bienes objeto de la reparación, el sujeto beneficiario y el contenido de la reparación Por ello se hace necesario clarificar estos conceptos que permitan decantar el concepto de reparación colectiva. En primer lugar,

"Existe una gran diferencia entre la reparación de daños colectivos y la reparación colectiva de daños individuales. La primera se fundamenta en el reconocimiento de los efectos que han sufrido las colectividades víctimas, como la destrucción de redes sociales, de propuestas políticas, de cosmovisiones, de alternativas de vida y procesos de construcción de memoria; mientras que la segunda, responde a una visión que limita los recursos y mecanismos para la aplicación de una política de reparación integral, en la medida en que homogeniza los daños causados individualmente a los miembros de una comunidad." (Subrayado fuera de texto). (Corporación AVRE, 2008, p. 5)

Según el Centro Internacional para la Justicia Transicional (ICTJ)(2009), del análisis de diversos caso de reparación colectiva a nivel internacional se ha encontrado que en contextos de pobreza, se puede confundir la reparación con programas propios de la justicia social y puede convertirse la reparación colectiva en una herramienta que no pretende otra cosa más que organizar los recursos que suponen escasos para la reparación dirigiéndolo a las víctimas como grupo, sin dirigirse a los verdaderos daños sufridos por las colectividades y grupos de allí que,

"Con base en esta aclaración la reparación colectiva, en el marco del derecho a la reparación integral de las víctimas, se orienta hacia el restablecimiento de los derechos vulnerados y a la reparación de los daños ocasionados a las comunidades, grupos u organizaciones afectadas por hechos de violencia sistemática o selectiva." (Corporación AVRE, 2008, p. 5)

Por lo tanto los bienes objeto de la reparación, consistirán en las herramientas y propuestas para el restablecimiento de los derechos vulnerados y la reparación de los daños ocasionados; en tanto que el sujeto beneficiario será un sujeto colectivo, ya sean comunidades, grupos u organizaciones.

La noción de víctima está necesariamente vinculada a la definición de violaciones de los derechos humanos o crímenes o conductas reprochables. Para delimitar los contornos de la definición de víctima es necesario preguntarse: ¿víctima de qué? La definición de las 
violaciones de los derechos humanos o de los crímenes que dan lugar a reparación en el marco de un programa administrativo obedece a las particularidades de la represión o la guerra de que se trate, al poder que puedan ejercer distintos actores de la sociedad -incluidos los grupos de víctimas, los propios responsables de las violaciones, la comunidad de derechos humanos y los movimientos feministas, entre otros- y a consideraciones políticas sobre disponibilidad presupuestal. (Díaz, 2009, p. 149)

De acuerdo con lo anterior se deberán aclarar dos elementos a tener en cuenta en la reparación colectiva; quienes son los sujetos beneficiarios y cuáles son los daños a reparar.

Vale la pena aclarar que el desarrollo conceptual de los Derechos Humanos, ha posibilitado el surgimiento de los derechos colectivos o de tercera generación, que en efecto problematizan la perspectiva primigenia de los derechos humanos individuales, por su condición de inherentes a la dignidad humana, sin embargo los mismos son conocidos como derechos de los pueblos y los connota un sentido de solidaridad, por ejemplo, el derecho a la paz, el derecho al desarrollo, entre otros. Se establecen entonces una nuevas categorías de derechos Humanos que pretenden superar la percepción individualista de los mismos.

Sin embargo, en materias de programas estatales de reparaciones conceptualmente es erróneo vincular las reparaciones colectivas con los derechos humanos colectivos, teniendo en cuenta que los fundamentos conceptuales de los mismos difieren. La teoría de las reparaciones se erigen sobre un concepto que tiene que ver con los daños perpetrados con ocasión de violaciones de obligaciones internacionales de los Estados, más no como expresiones de los derechos que se relacionan con la satisfacción de bienes y necesidades para que la vida sea digna de ser vivida. (Derechos de libertad e igualdad)

En el mismo orden de ideas, entonces retomamos el concepto de sujetos colectivos que tienen que ver más con la idea de grupos o comunidades que comparten vínculos relacionales que los sitúan en la historia. Así las cosas,

La definición de víctimas colectivas no parece tan sencilla como la definición de víctimas individuales. La comunidad internacional ha llegado a un amplio consenso en la definición de víctima, que si bien también alude a aquellas personas que hubieren sufrido daños colectivamente, no precisa todos los elementos para definir quiénes son víctimas colectivas. (Díaz, 2009, p. 150)

De allí que se parte de identificar quien es sujeto colectivo para luego definir que sujetos colectivos son víctimas y por tanto beneficiarios de reparación colectiva.

"Los sujetos colectivos son aquellos grupos de individuos en los que los fines e intereses van más allá de los de cada uno de los individuos que conforman el sujeto colectivo. Se origina así una voluntad y un interés que nacen y se sustentan en la voluntad y el interés de los individuos que integran el grupo." (Chacón, 2010, Pág. 11)

Encontramos aquí dos elementos que definen a los sujetos colectivos, la voluntad y el interés 
común, que se presenta como diferente de la voluntad a interés de los miembros de dicho colectivo. Pero más allá de los términos jurídicos "Las comunidades, las organizaciones y los sectores sociales, comparten apuestas conjuntas que dan cuenta de proyectos de vida colectivos asociados a la expresión de intereses compartidos, sobre la base de los cuales se construye identidad y sentido de pertenencia." (Corporación AVRE, 2008, Pág. 14)

De allí que se deba recocer la existencia de un proceso identitario al interior del grupo, en el que sus miembros se reconocen como parte del mismo.

"Puede decirse que el sujeto colectivo es un grupo que dispone de "unidad de sentido", diferente de la mera suma de los individuos que conforman el grupo, con un proyecto colectivo identitario. Cuando el sujeto colectivo antecede las violaciones de los derechos humanos de que se trata, justamente por su carácter de sujeto colectivo podría pensarse que experimenta daños de naturaleza colectiva." (Díaz, 2009, p. 161) (Subrayas fuera de texto)

Además de lo anterior encontramos aquí otro elemento: la preexistencia del grupo a efectos de identificar los daños, dado que la victimización se produce sobre un sujeto colectivo preexistente, la reparación por tanto debe dirigirse a ese grupo, no a uno que se organice con posterioridad, aunque sus miembros sean los mismos.

Por lo tanto tenemos cuatro elementos que identifican al sujeto colectivo a efectos de la reparación: $i$. identidad común ii. Voluntad común iii. Intereses comunes y iv. preexistencia a la violación.

Por su parte la Corporación AVRE, para el caso colombiano presenta cuatro factores a tener en cuenta cuando se trata de identificar al sujeto colectivo:

"En el marco de la violencia sociopolítica y el conflicto armado, hablar de víctimas colectivas nos remite a aproximarnos a la situación de discriminación, exclusión, marginalidad y estigmatización a la que se ven sometidos en Colombia determinados sectores y grupos sociales en razón de:

1. Su identidad étnica, racial y cultural (las comunidades indígenas y afrodescendientes, entre otros);

2. Sus convicciones ideológicas y su quehacer político (los opositores políticos, los sindicalistas, los líderes sociales, los objetores de conciencia, los defensores de Derechos Humanos);

3. Sus condiciones socioeconómicas y su ubicación geográfica (las comunidades campesinas, que viven en áreas rurales o se encuentran desplazadas en las ciudades);

4. Su identidad, orientación o preferencia sexual (las mujeres, los gays, las lesbianas, los bisexuales y los transgeneristas)." (Corporación AVRE, 2008, p. 28) 
Encontramos en esta propuesta dos elementos, el primero de ellos que tiene que ver con el carácter jurídico o no del colectivo, dado que no se necesitaría que el mismo estuviese reconocido como persona jurídica, es el caso de las comunidades campesinas. El segundo, vincularía al colectivo a reparar por las condiciones de exclusión y marginación que son la causa de la victimización y que generan un impacto desproporcionado del mismo, como es el caso de las mujeres, la comunidad LGBTI, etc. que debido a patrones culturales estructurales han sufrido la violencia debido a la pretensión de imponen un modelo de sociedad homogenizado, y que por tanto merecen que se visibilice sus especiales circunstancias y se les repare por dicho daño independientemente que estén constituidos en un grupo.

Cuando preexiste un sujeto colectivo, puede razonablemente considerárselo como víctima si hubo: violación de derechos colectivos o violación masiva o sistemática de derechos individuales de sus miembros o violación de derechos individuales con graves impactos colectivos, como el asesinato, la desaparición o la tortura de autoridades políticas, administrativas y religiosas tradicionales. (Díaz, 2009, p.161)

Lo que nos deja claro que el concepto de víctimas colectivas no solo responde a la masividad de la violación, sino a los efectos colectivos del daño causado, como podría suceder por ejemplo, en el asesinato de un líder de una comunidad indígena, en el que el ataque se perpetra intencionadamente en su condición, con la finalidad de debilitar al grupo, por lo que no solo la víctima directa resulta perjudicada sino todo el grupo al cual pertenecía.

Todos estos elementos nos permiten aproximarnos un poco más a la definición de sujetos colectivos a efectos de la reparación de cara a un proceso de reparación colectiva.

\section{b. LOS DERECHOS VULNERADOS Y EL DAÑO COLECTIVO}

El daño ha sido definido como el menoscabo que sufre un derecho reconocido a su titular. En el campo que nos ocupa, son todas aquellas afectaciones experimentadas por un grupo o comunidad como consecuencia de la violación de Derechos Humanos de sus miembros con la finalidad de someter o desarticular al grupo.

Un daño colectivo se genera cuando un hecho de violencia sociopolítica lesiona o pone en riesgo la identidad colectiva y el desarrollo cultural, social y político de una comunidad, organización o sector social [...] Es importante reconocer que la valoración de los daños no es universal para todas las personas y colectividades; depende de sus particularidades culturales, étnicas, políticas, generacionales y de género, de la magnitud de los hechos violentos y del contexto en el que ocurren. (Corporación AVRE, 2008, p. 13)

De allí que el daño pone en riesgo los elementos que constituyen el colectivo y que lo definen como tal por lo que su valoración deberá tener en cuenta los elementos diferenciales de cada uno.

De acuerdo con la Corporación AVRE (2008) los tipos daños colectivos se manifiestan como: daños a la identidad colectiva, daños a los liderazgos y a la participación, daños a la dignidad y al buen nombre, daños en la identidad cultural y en los elementos simbólicos y ruptura de las dinámicas de 
relación de los colectivos. Estos daños generan Impactos emocionales y cambios de referentes en los grupos y comunidades victimizadas. Por otra parte existen otros elementos que son consustanciales al daño colectivo: la intencionalidad del mismo y el contexto de impunidad en que se desarrollan, en ese se plantea que,

"Hay que añadir dos aspectos para valorar y dimensionar los daños colectivos. Por un lado, la intencionalidad de la violencia sociopolítica reflejada en los propósitos de fragmentar los procesos organizativos, generar terror en comunidades para poder ejercer el control, destruir redes, desestimular las propuestas políticas o sociales de la organización, aislar a los miembros, y en los casos más extremos, la desaparición o exterminio de comunidades y organizaciones. Por otro lado, el contexto de impunidad en que ocurren las violaciones, el cual contribuye a incrementar el dolor, a generar nuevos daños y a intensificar los ya existentes." (Corporación AVRE, 2008, p. 13)

Estos elementos sobredimensionan el daño, dado que el primero indica que toda violación colectiva se produce con una finalidad por lo que responden patrones sistemáticos de violación de derechos humanos y la segunda conduce a la revictimización en contextos en los cuales estos daños no se visibilizan ni se les da respuestas por que los daños se basan en esquemas estructurales del orden político social y económico de dichas sociedades.

Los procesos de violencia generalizada en los que se producen victimizaciones masivas responden a proyectos de trasformación de las sociedades que pretenden imponer nuevos valores y formas de vida aun a costa del supuesto sacrificio de algunos. En ese sentido la exigencia de la reparación colectiva se convierta en un esfuerzo por visibilizar esas prácticas y sus responsables directos e indirectos, por lo tanto en toda definición de daños colectivos se debe observar siempre las causas y la intencionalidad de los mismos, articulándose con las políticas y programas sobre memoria histórica, de allí la importancia del rescate de la memoria.

Esto amplia el espectro de la reparación colectiva, que ya no solo se dirige a los grupos directamente afectados, sino que se hace necesaria para la sociedad entera afectada por estos procesos,

[...] y es que en los casos de graves violaciones de los derechos humanos y violencia extrema no solo las víctimas individuales resultan dañadas, sino que es toda la sociedad quien acaba siendo traumatizada. Es por ello que el proceso de reparaciones no se tiene que enfocar exclusivamente en las víctimas individuales, sino que también se tiene que dirigir al conjunto de la sociedad, que también necesita de un proceso de reparación social." (Gómez, 2006, p. 35)

Por lo tanto al lado de las reparaciones individuales se debe realizar un proceso de reparación colectiva que busque superar los efectos de la violencia no solo en los grupos sino también en la sociedad misma.

Guarda pertinencia con el tema que tratamos, el ejercicio realizado en Colombia referido a la sistematización de siete pilotos de reparación colectiva (La Libertad en San Onofre, Sucre; El Salado, municipio del Carmen de Bolívar en Bolívar; Inspección El Tigre, en el Putumayo; Universidad de 
Córdoba, la Asociación de Trabajadores Campesinos de Carare, en Santander y la Comunidad Negra de Buenaventura, en el Valle, Gabarra municipio de Tibú en el Norte de Santander) realizados entre 2007-2011 por la OIM, cuyos resultados se plasmaron en el texto "Del daño a la reparación colectiva: la experiencia de siete casos emblemáticos", en el mismo, utilizando técnicas de investigación social, se hallaron como categorías emergentes respecto de los derechos y respecto de los daños los siguientes:

En cuanto a los derechos se preestablecieron cuatro (4) categorías, las cuales se denominaron $i$. derechos individuales vulnerados con impacto colectivo, ii. Derechos individuales violados generalizada y sistemáticamente con impacto en el colectivo iii. Derechos colectivos iv. Violación de derechos de sujetos colectivos. En las tres primeras categorías se reiteran las siguientes violaciones de derechos: derecho a la vida, integridad, dignidad, libertad, buen nombre, DESC, derecho a la libre asociación, derecho a no ser desparecido. En la cuarta categoría solo se reitera el daño al medio ambiente y a derechos culturales.

Los daños identificados por estos pilotos, son también agrupados en categorías a saber:

Económicos, psico-sociales, políticos, culturales y comunitarios, identificándose por cada uno de los ejercicios, similares tipos de daños, por ejemplo, en los económicos sobresale la agudización de la probreza, afectación a los servicios de saneamiento, cambios de uso del suelo, ruptura de ciclos productivos y pérdida de seguridad alimentaria.

En los psico sociales se identifican los daños que tienen que ver las afectaciones relacionadas con los miedos por los padecimientos sufridos y que hacen que se pierda capacidad de agencia.

En los políticos sobresales reducción en la participación ciudadana, pérdida del sentido de la norma, abandono de la acción estatal, y corrupción. Y por último en los culturales y comunitarios, la desintegración de la comunidad, pérdida de la cultura, cambio en las relaciones sociales, perdida de los lazos organizativos.

\section{c. LAS MEDIDAS DE REPARACIÓN COLECTIVA}

Se ha venido afirmando que la reparación colectiva también debe ser integral, de tal suerte que las medidas que se adopten deben ser contextualizadas a los colectivos y responder a cada uno de los componentes de la reparación, en consonancia con elementos a los cuales nos hemos referido, el derecho violado y el daño. La ley de víctimas taxativamente plantea:

ARTÍCULO 69. MEDIDAS DE REPARACIÓN. Las víctimas de que trata esta ley, tienen derecho a obtener las medidas de reparación que propendan por la restitución, indemnización, rehabilitación, satisfacción y garantías de no repetición en sus dimensiones individual, colectiva, material, moral y simbólica. Cada una de estas medidas será implementada a favor de la víctima dependiendo de la vulneración en sus derechos y las características del hecho victimizante. 
Así las cosas existen muchas posibilidades concretas que pueden ajustarse a cada uno de los componentes de la reparación, por ejemplo vemos que las medidas abarcan un amplio espectro que va desde el familiar componente indemnizatorio, hasta medidas de satisfacción, por ejemplo disculpas públicas, monumentos a la memoria.

En casos de restitución, la Corte Interamericana ordenó la implementación de programas de vivienda para quienes decidieran retornar a la región y en el caso de Ituango, ordenó que el programa de vivienda que se implementase se realizaran en el lugar donde se encuentran los familiares de las víctimas. (Corporación AVRE, 2008, p.51)

\section{CARACTERÍSTICAS DE LOS PROCESOS DE REPARACIÓN COLECTIVA}

\section{a. PROCESOS PARTICIPATIVOS}

El éxito de un proceso de reparación colectiva lo asegura la participación del colectivo que sufrió la victimización, este aspecto es importante en la medida que necesariamente implica un trabajo con comunidad y la preexistencia de instituciones que puedan abordar el diseño de los planes de reparación desde las necesidades de los colectivos y no por imposición institucional. La participación implica el fortalecimiento y la recuperación de la confianza de la mano con el surgimiento de liderazgos y renovada confianza e las instituciones.

\section{b. LA INTEGRALIDAD DEL PROCESO DE REPARACIÓN COLECTIVA (INTERNA Y EXTERNA)}

La reparación debe ser integral, quiere decir ello que las medidas de reparación deben per se tributar a la dignificación de las víctimas, pero al tiempo, las mismas implican la satisfacción de una sociedad, que ha acudido a los mecanismos de justicia transicional como forma de abordar pasados traumáticos. En ese sentido la victimización es un proceso complejo que afecta no solo a individuos y grupos específicos sino que daña a la sociedad entera, de allí que la reparación debe construirse en un proceso que encierre diferentes elementos. (Gómez, 2006), propone la idea de integralidad externa e interna así,

"Un proceso de reparaciones tiene que ser integral, tanto en su vertiente externa como interna. A la integralidad externa ya hemos hecho referencia cuando hemos analizado las interconexiones entre verdad, justicia y reparación. Un programa de reparaciones no se puede concebir sin, al mismo tiempo, avanzar en el ejercicio del derecho a la verdad y del derecho a la justicia. La reparación no puede concebirse como un mero sustituto de la verdad y la justicia, como en ocasiones se pretende, ya que ello equivaldría a querer comprar el silencio y la injusticia. Por su parte la integralidad interna hace alusión a que las diferentes medidas de reparación a las víctimas y a la sociedad tienen que ser coherentes y apoyarse mutuamente. La reparación no tienen una dimensión meramente económica, sino que se tiene que abordar como un intento omnicomprensivo de reparar el daño causado a las víctimas y de buscar un nuevo equilibrio político y social, proceso en el que las diferentes medidas de reparación pueden jugar papeles distintos pero complementarios." (Gómez, 2006, p. 38) 
La integralidad externa, tiene que ver por tanto, con las vinculaciones de la reparación con la verdad y la justicia en el marco de un proceso de justicia transicional, en el que a las víctimas no solo se le debe garantizar la reparación sino que se tiene que garantizar los derechos: a la justicia con la investigación, juzgamiento y sanción de los victimarios directos e indirectos; y a la verdad con identificación de las causas y finalidades de que no solo generaron los hechos victimizantes sino que sustentaron el conflicto.

Por su parte la integralidad interna responde a las medidas que se deben tomar para satisfacer los anhelos de reparación de cada uno de los colectivos afectados, estas medidas son las de indemnización, restitución, rehabilitación, satisfacción y garantías de no repetición, pero que se vinculan necesariamente en su contenido con las propuestas de los grupos y comunidades de acuerdo a los daños específicos sufridos por cada una.

"La reparación colectiva se encuentra en estrecha relación con los derechos a la verdad y a la justicia, e implica la adopción de un enfoque diferencial para identificar los daños ocasionados a comunidades y sectores sociales, y para adoptar las respectivas medidas de reparación. En este sentido, es necesario elaborar un inventario de daños en cada colectividad víctima, teniendo en cuenta sus particularidades étnicas, generacionales, políticas, culturales y de género, con el fin de establecer una serie de medidas específicas de reparación que contemplen las especificidades del grupo afectado y que estén orientadas al reestablecimiento de los derechos vulnerados. Bajo esta perspectiva, la reparación colectiva comprende los componentes de restitución, indemnización, rehabilitación, medidas de satisfacción y garantías de no repetición." (Corporación AVRE, 2008, p. 5-6)

\section{c. LA PERSPECTIVA TRANSFORMADORA}

La perspectiva transformadora, tiene que ver directamente con el concepto de violencia estructural planteada por Galtung, como una de las manifestaciones de violencias al lado de la directa y la cultural, y "trata de una violencia intrínseca a los sistemas sociales, políticos y económicos mismos que gobiernan las sociedades, estados y el mundo" (Calderón, 2008). Pueden diseñarse un sinnúmero de programas gubernamentales de reparación con fundamento en el daño causado sea individual o colectivamente, pero si no se transforma el contexto que efectivamente desencadenó en la sociedad la exclusión social y el levantamiento de las armas o el derrocamiento de los líderes democráticos, no podría hablarse de un trasfondo de transformación de conflictos para que la paz y los acuerdos posconflicto sean duraderos y sostenibles. En ese sentido la vocación de transformadora de la reparación, debe ir más allá de la simple restitutio in integrum, mejorando la calidad de vida de las víctimas con vocación de transformación social.

La reparación en general y la reparación colectiva en particular, en el marco de un proceso de justicia transicional, no se puede concebir como un momento específico sino que constituye en un proceso político que busca la trasformación de paradigmas estructurales, sociales, económicos y políticos que dieron origen al período de conflicto o violencia, para la reconstrucción de la sociedad.

Nos encontramos ante un proceso político que busca la reconstrucción de la comunidad 
política, un nuevo equilibrio en la sociedad en el que las víctimas sean reconocidas en su condición de víctimas y pasen a ocupar un nuevo papel en el espacio político y social. En este sentido la reparación pasa a formar parte de un proceso de justicia reparadora y trasformadora, una justicia que lo que pretende, en definitiva, es la plena reparación de las víctimas y la transformación de la sociedad hacia una sociedad más justa en que las víctimas de las violaciones del pasado ocupen su lugar. (Gómez, 2006, p. 35)

El Centro de investigación para el Derecho, la Justicia y la Sociedad (DeJuSticia) ha propuesto el concepto de "Reparación Trasformadora" para aplicar a sociedades que han atravesado por un conflicto armado y en la cual la mayor parte de la población se encuentra en situación de pobreza y exclusión social. Dado que:

“El principio de reparación integral genera paradojas y dilemas difíciles en sociedades que intentan saldar cuentas frente a violaciones graves y masivas a los derechos humanos, ocurridas en regímenes autoritarios o durante conflictos armados. Estas sociedades enfrentan también usualmente profundas desigualdades sociales y económicas y una pobreza extrema muy extendida. (...)

En términos jurídicos, es una tensión entre el deber del Estado de reparar a las víctimas de violaciones graves a los derechos civiles y políticos, debido a crímenes atroces, y el deber del estado de satisfacer los derechos económicos, sociales y culturales, en especial de poblaciones pobres y vulnerables." (Uprimny, 2010 p. 236-237)

El propósito consiste en que no se debería restaurar a la víctimas a la situación de precariedad previa a la victimización, si no trasformar esas situaciones por ser injustas y por haber sido en parte causa de la victimización, y se fundamenta en el hecho de que ciertas sociedades no han alcanzado la justicia distributiva, por lo que aplicar el principio restitutorio de las reparaciones podría conducir a devolver a las víctimas pobres a situaciones de precariedad y exclusión social, por lo que este principio es aplicables a sociedades justas en términos distributivos.

En cuanto a su alcance se manifiesta que las reparaciones deben estar fundadas en principios de justicia correctiva pero también en principios de justicia restaurativa, por lo que el deber de reparación integral debe entenderse como principios o mandatos y no como reglas cerradas dado que este solo se podrá aplicar cuando no violente los imperativos de justicia distributiva.

Por ello, en ese tipo de situaciones es razonable defender la idea de que las reparaciones deben tener una vocación transformadora y no puramente restitutoria, esto es, que las reparaciones no solo deben enfrentar el daño que fue ocasionado por los procesos de victimización, sino también las condiciones de exclusión en que vivían las víctimas y que permitieron o facilitaron su victimización. (Uprimny y Saffon, 2009, p. 35)

El enfoque trasformador está implícito en los proceso de reparación colectiva, dado que los conflictos armados y las graves alteraciones del orden público no surgen de la nada sus causas se fundamentan en unas estructuras políticas y sociales que le dan vida. Por lo tanto todo proceso de reparación que se precie de ser medianamente justo debe trasformar esas realidades para construir una sociedad más justa e igualitaria. 
Si bien en el marco de la Ley 1448 de 2011 se abre con esperanza un nuevo camino hacia la reconciliación, no lo es menos la existencia de actores e instituciones que pueden actuar como facilitadores de los procesos, o todo lo contrario, sobre todo en los aspectos que tienen que ver con políticas públicas más ligadas al territorio y a enfoques diferenciales. Con lo cual se transitarán caminos de retos y oportunidades, pero también de dificultades frente a los procesos de reparación colectiva. Por ello se hace necesario el fortalecimiento y articulación de las instituciones de orden nacional y territorial, la claridad de cuales colectivos pueden calificar para la ruta de reparación colectiva y los que no, la planificación de los presupuestos públicos que respaldaran dichos programas de reparación y sobre todo la voluntad política que posibilite pensar en caminos de reconciliación.

\section{CONCLUSIONES}

La justicia transicional es el marco contextual en el que se desarrolla el concepto de reparación colectiva, se presenta en dos dimensiones, una de carácter judicial que privilegia la investigación de los hechos ocurridos y la imputación de responsabilidades a los perpetradores y una dimensión política que integra una serie de procesos que conducen a la trasformación social e institucional de los Estados. En este proceso los diferentes gobiernos implementan medidas tales como: Comisiones de la Verdad, Programas de reparación; leyes de alternatividad penal; y diferentes reformas institucionales, que pretenden la satisfacción de los derechos a la verdad, la justicia, la reparación y las garantías de no repetición.

Por lo tanto la justicia transicional se conforma como un proceso jurídico y político en el que el que se pretenden lograr a través de diversos mecanismos e instrumentos excepcionales, la trasformación de las estructuras socio-políticas que fueron causa de conflictos y tensiones y que se presenta como respuesta a las graves, masivas y sistemáticas violaciones de derechos humanos para la que los procesos y normas ordinarias tanto nacionales como internacionales no tienen respuestas adecuadas.

En marco de estos procesos se produce la necesidad, debido a la magnitud de los daños experimentados, de establecer mecanismos que tiendan a satisfacer los derechos a la indemnización, restitución, rehabilitación, satisfacción, y garantías de no repetición para los grupos, comunidades y la sociedad que se han visto afectada como consecuencia de la magnitud y masificación de las violaciones; esto es desarrollar herramientas para las reparaciones colectivas orientadas identificar derechos vulnerados, daños causados y tipos específicos de medidas en contexto.

Cuando hablamos de reparación colectiva, hablamos de realidades que desbordan los estándares tradicionales del derecho a la reparación: ante la alegada imposibilidad de los Estados de reparar individualmente a grandes números de personas y la necesidad de visibilizar el impacto en los grupos y en la sociedad de períodos de violencia, de allí que la idea de reparación colectiva se presente como necesaria en el marco de lo que se entiende como justicia transicional.

Los procesos de reparación colectiva implican ejercicios de definir y redefinir lo que es "un 
colectivo" desde la teoría, para que la descripción normativa pueda sin dificultad ser aplicada con exactitud, porque en los procesos de reparación no solo se definen parámetros de justicia sino parámetros de democracia y de transformaciones sociopolíticas.

\section{REFERENCIAS BIBLIOGRÁFICAS}

BERISTAÍN, C. (2010) "Diálogos sobre la reparación: Qué reparar en los casos de violaciones de derechos humanos". San José de Costa Rica: Instituto Interamericano de Derechos Humanos.

BONET, J. y ALIJA, R. (2009) “Impunidad, derechos humanos y justicia transicional”. En: Cuadernos Deusto de Derechos Humanos Núm. 53, Bilbao: Universidad Deusto.

BRITO, D. (2010) “Justicia Restaurativa, Reflexiones sobre la experiencia de Colombia”. Colección Cultura de Paz. Ecuador: Universidad Técnica Particular de Loja.

CALDERÓN, P. (2009) "Teoría de los Conflictos de Johan Galtung". En: Revista de paz y conflictos No. 2. España: Universidad de Granada. Instituto de Paz y Conflictos.

CENTRO INTERNACIONAL PARA LA JUSTICIA TRANSICIONAL. (2009) “¿Qué es justicia transicional?”. Disponible em:<http://ictj.org/sites/default/files/ICTJ-Global-Transitional-Justice-2009Spanish.pdf>.

CENTRO INTERNACIONAL PARA LA JUSTICIA TRANSICIONAL (ICTJ) y Centro de Estudios de Derecho, Justicia y Sociedad (DeJusticia) (2009). "Reparar en Colombia: los dilemas en contextos de conflicto, pobreza y exclusión. Colombia".

CHACÓN, A. (2008) “Alcances de la reparación colectiva”. Colombia: Defensoría del Pueblo.

CORPORACIÓN AVRE (2008) “Dimensión política de la reparación colectiva”. Voces de memoria y dignidad. Cuaderno de Reflexión sobre Reparación Integral. Colombia.

DíAZ, C. (2009) “La Reparación Colectiva: Problemas Conceptuales en perspectiva comparada". En: Reparar En Colombia: Los Dilemas En Contextos De Conflicto, Violencia y Exclusión. Colombia: ICTJ.

ESTATUTO DE ROMA DE LA CORTE PENAL INTERNACIONAL (2002) Aprobado el 17 de julio de 1998 por la Conferencia Diplomática de Plenipotenciarios de las Naciones Unidas sobre el establecimiento de una corte penal internacional. Distr. General A/CONF.183/9.

GÓMEZ ISA, F. (2006) “El Derecho a la Memoria”. España: Editorial Alberdania.

CENTRO INTERNACIONAL PARA LA JUSTICIA TRANSICIONAL (2009) "Informe de Rabat". Disponible en: $<$ http://ictj.org/sites/default/files/ICTJ-Morocco-Reparations-Report-2009-Spanish.pdf>. Acesso em 12 de agosto de 2014.

JIMÉNEZ, C. (2010) “El campo psicosocial conceptos e implicaciones". En: Tareas Pendientes: propuesta para la formulación de políticas públicas de reparación en Colombia. Colombia: Centro Internacional para la Justicia Transicional (ICTJ). 
OFICINA DEL ALTO COMISIONADO DE LAS NACIONES UNIDAS PARA LOS DERECHOS HUMANOS (2006) "Instrumentos del Estado de Derecho para Sociedades que han salido de un conflicto, iniciativas de enjuiciamiento". Naciones Unidas New York.

ORGANIZACIÓN INTEGRAL PARA LA MIGRACIONES (OIM), Misión Colombia (2012) "Del daño a la reparación colectiva: La experiencia de siete casos emblemáticos".

UPRIMNY, R. y GUZMÁN, D. (2010) “En búsqueda de un concepto transformador y participativo para las reparaciones en contextos transicionales". En: Revista Colombiana de Derecho Internacional. Colombia: Pontificia Universidad Javeriana. 